\title{
The Research on the Collaborative Development of Intelligent Retail Business Ecosystem
}

\author{
Lu Ying ${ }^{1}$, Fan Zhipeng ${ }^{1}$, Liu Yan ${ }^{1}$, Zhang Bing ${ }^{2}$ \\ ${ }^{1}$ School of Computer and Information Engineering, Harbin University of Commerce, \\ Harbin 150028, China \\ ${ }^{2}$ Network and Education Technology Center, Harbin University of Commerce, Harbin \\ 150028, China \\ 0451_ly@sina.com
}

\begin{abstract}
With the support of technologies such as Internet, big data and artificial intelligence, virtual platform transactions are becoming more and more extensive. Traditional retailers, product suppliers and consumers can implement corresponding trade activities in the network platform, open up their own sales network channels, and complement each other with traditional retailers, so as to achieve coordinated development in the competitive environment. Based on the current situation of China's retail industry development, this thesis analyzes the causes of the Intelligent Retail Business model and discusses the strategies of the intelligent business ecosystem's collaborative development on the basis of the Business Ecosystem theory, the Wheel of New Retail theory, the Collaborative theory and the Customer Experience theory.
\end{abstract}

Keywords: Intelligent Retail, business ecosystem, collaborative development

\section{Introduction}

In the Internet environment, the traditional retail structure is constantly updated, and the relationship between retail industry and modern information technology is increasingly close. After several major changes, China's retail industry has entered the era of Intelligent Retail. Based on the Internet of things, artificial intelligence, big data and Internet technology, Intelligent Retail has realized the digitalization of products, payment and user communication, and the intellectualization of operation and retail, providing customers with high quality goods and services. Traditional retail is aimed at the mass market, provides a batch of goods, while in the modern Intelligent Retail, advanced sensing technology will give enterprises the insight they need to personalize each consumer, which can be connected to external resources through flexible realize the personalized demand, can also through the interactive and intelligent algorithm to make delivery more efficient, the enterprise can better grasp of consumer demand, to carry out targeted marketing and personalized service, improve customer experience to increase consumer purchase rate. It is necessary to mobilize the initiative in all aspects of production and operation, including producers, operators and consumers, and promote the sound and orderly development of the business ecosystem. This is based on the coordinated development of all parts of the business ecosystem.

Article history:

Received (March 23, 2019), Review Result (May 2, 2019), Accepted (June 11, 2019) 


\section{Current Situation of China's Retail Industry}

Since the mid nineteenth century, retail formats have undergone several important changes. The emergence of these five formats, such as department stores, chain stores, supermarkets, shopping centers and E-commerce, is of milestone significance. The world's retail industry is ushering in new opportunities for development with every change. In recent years, the progress of technology has greatly promoted the convenience of shopping, broken the boundaries of time and space, shortened the distance between offline stores and online shopping platforms, and the retail format has developed in the New Retail direction of online and offline integration. The sales scale of China's retail market has grown steadily, and the growth rate has declined in recent years. In 2018, the national retail sales volume of commodities reached 33.8 trillion $\mathrm{RMB}$, an increase of $8.9 \%$ year-on-year. Although the growth rate dropped 1.3 percentage points from the same period of last year, it is still at a high level. Figure 1 shows China's retail sales and growth rate in 2010-2018.

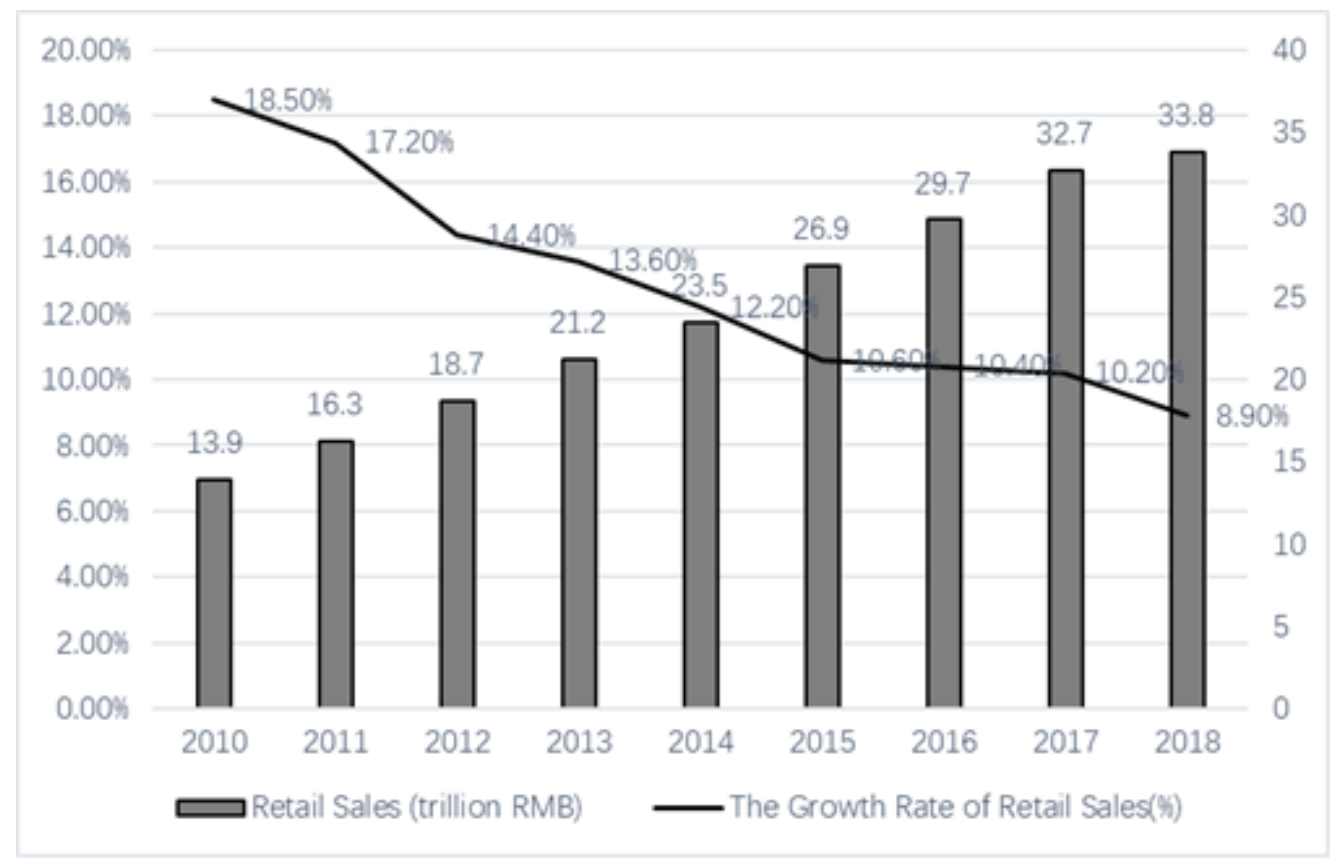

Figure 1. China's retail sales and growth in 2010-2018

\section{The Overview of Related Theories}

\subsection{The Business Ecosystem}

The concept of business ecosystem was put forward by Moore, an American scholar in 1993. He believed that in a market environment, enterprises are no longer isolated individuals, but should form "economic consortium based on the interaction between organizations and individuals, that is, the formation of a business ecosystem. [1] After Moore, many scholars began to pay more attention to the research of business ecosystem. Peltoniemi, Vuori[2] and Pierce[3] regard business ecosystem as the organizational structure with stability and adaptability, which is finally promoted by each member although they pursue different goals. In the business ecosystem, its main components include core enterprises, expanding enterprises, relevant social organizations, other members and the environment. 


\subsection{The New Retail Round Theory}

Intelligent Retail is also called the "New Retail". In 1996, Japanese scholar Maso Nakanisi re-examined the traditional "The Wheel of Retail[4]" and "vacuum zone" theory and put forward "The wheel of New Retail". "The Wheel of Retail" believes that the initial pursuit of the retail industry into the market is the basic strategy of low cost, low price and low gross profit. After successfully entering the market, retail enterprises will turn to improve the quality of service in response to fierce competition, and gradually becomes the same high cost, high price, and high gross profit characteristics as the traditional retailers being replaced, then turn to the object of a new generation of retail innovation. Different from the "The Wheel of Retail", the "The Wheel of New Retail" believes that the retail industry can get rid of price competition through technological innovation, emphasizing that the retail industry should be guided by technological innovation to improve the logistics distribution, cost control, information management and other aspects, so that it can really promote the development of the retail industry. "The Wheel of New Retail" theory explains the basic motivation and development logic of "New Retail". When the restriction conditions of the technology edge are changed, the original technology edge will be changed. Typically, new technology applications will cause technology edge to move down to the right and then the New Retail formats will emerge. The New Retail mode is the new growth point of the retail industry. The construction degree of the channel platform and the support of the new technology of the intelligent retail will be the key to its final success.

\subsection{The Synergy theory}

The Synergetic theory is a branch theory of science system, which was founded by Hermann Haken, a famous German theoretical physicist. Its connotation is that multiple independent subjects or systems form cooperative groups, so as to show more superior business effects. In the cooperative group, each subject or system has the function of mutual cooperation, cooperation and domination, which is different from the original qualitative change in the process of mutual connection and development. Since then, with the deepening of the research, he also introduced information theory into the study of synergetic macro method, using it to "deal with an open system far from the equilibrium state" [5]. According to the Synergy theory, in the process of seeking cooperation and development, each member of retail business ecosystem has the interaction of knowledge, technology, innovation and value. When this interaction breaks through the critical point, the whole system will change qualitatively and form the coordination effect, so that the overall function of the system is greater than the sum of local and individual functions, and then the whole system will be realized optimized configuration.

\subsection{The Customer Experience Theory}

In the New Retail environment, the business practice of improving customer experience is ahead of its theoretical development, but there is little discussion on this issue in the academic community, and the theoretical research is still in the initial stage, so it is difficult to give guidance to the business practice. However, the essence of new retail is how to improve the customer experience to carry out the innovation of retail business mode in the Internet environment. Therefore, studying the topic of customer experience in the new retail format has become the theoretical foundation for supporting the New Retail development. Customer's offline experience is a series of feelings generated by direct contact with retail stores, including 
product utility, service process, store environment, etc. The online experience of customers is an interactive process with a series of services provided by online enterprises. The customer experience under the New Retail format refers to a series of psychological feelings which are affected by the marketing activities of the enterprise. And the comprehensive consumption experience produced by the consumption process of various channels refers to the overall feeling of the customer's purchase experience in the consumption process.Rose and other scholars compared the differences between the customer experience in the e-commerce environment and the physical shopping environment: firstly, the customer's contact with the goods is different, in the physical shopping environment, the customer directly contacts with the goods, while in the e-commerce environment, the customer contacts with the goods virtually. Secondly, the amount of information provided is different. Under the physical environment, some limited commodity information is provided, while the E-commerce environment can provide a large number of commodity related information for customers. Thirdly, the time and space of consumption are different. In the physical environment, consumers can only consume in a fixed place and a fixed business time, while in the E-commerce environment, consumers can buy goods in any place at any time. Fourthly, the way of commodity information transmission is different. In the physical environment, commodity information is transmitted through various forms of experience, while in the E-commerce environment, commodity information is mainly transmitted through vision and hearing.

\section{The Reason of the Intelligent Retail Business Model}

\subsection{The Change of Consumer Demands}

With the constantly increasing disposable income and the improvement of living standards, the consumers would like to pay more attention to the shopping experience and feelings rather than to the quality and the price of goods. At present, the consumption upgrading presents the characteristics of demand personalization, purchase entertainment, socialization, word-ofmouth, purchase multi-channel, simple consumption and so on. If customers feel effective and satisfied with the purchase process and results, they will promote the purchase behavior again to a large extent. Customer experience is influenced by customers' internal emotion and external environment. In the process of consumption, customers are not only affected by the satisfaction of functional interests of products and services provided by enterprises, but also affected by the satisfaction of emotional interests they experience when using products or enjoying services. These functional interests and emotional interests work together to form customers' shopping experience.

\subsection{Traditional Retail Develops Slowly}

In the traditional retail classification, entity retail and online retail are two independent models. In recent years, the development of entity retail is imbalance. The key costs that affect the profits of retail enterprises, including store rental fees, labor costs, warehousing costs, etc., all have an upward trend to some extent. Besides, the e-commerce diverging customers can't be ignored, either. These factors lead to the entity retail performance declining. Compared with the development of physical retail, the online retail market acts active, and the core of online retail is traffic. The users of online shopping have increased sharply from the beginning to the current slow increase, the growth of traffic is slow, and the cost of acquiring customers keeps rising. Both physical stores and retail website have adverse factors that restrict their growth. Therefore, retail enterprises urgently need to solve their survival problems through business 
model innovation to bring sustainable development for enterprises. Under the background of the integration of Big Data, Cloud Computing and other technologies with retail, the emergence of Intelligent Retail business model is inevitable.

\subsection{The Development of New Technology}

In this New Retail revolution, Big Data, Cloud Computing, the Internet, Artificial Intelligence and other emerging technologies play a crucial role. We can say that there is no new retail without these new technologies. In this round of technological progress, many innovative applications are based on the intelligent and digital, such as Automatic Speech Recognition, Visual identity, face recognition system, etc., the new technology into new applications can strengthen the reality and virtual embedded with each other, intelligent experience can be closely integrated with consumers. That can realize the increase in performance value of the new retail mode service. These new technologies can grasp the consumer demand and behavior by not only according to the history of consumer behavior and the real demand of dynamic but also provide strong support for the enterprise production and precision marketing, to make the speed of the information circulation on the market greatly increase. Enterprises can grasp the dynamics of consumers in real time, it can well connect the participants in the supply chain, recombine entity shop, e-commerce sites, Apps, social media and instant messaging software, build an all-weather, multi-dimensional retail ecosystem to achieve seamless shopping experience and Omni-channel in consumer demand.

\section{Coordinated Development Strategy of Intelligent Retail Business Ecosystem}

\subsection{Integrated Development and Co-evolution of Physical Retail and Online Retail}

In recent years, many traditional retail enterprises have explored the online platform, and the online platform has also actively sought entity retail cooperation, gradually forming the mode of integration and development of traditional retail and e-commerce enterprises. This is a slow process of mutual complementation and integration. Factors such as differentiated real-time strategies will lead to conflicts in the process of collaboration [6]. Therefore, the elements of the retail business ecosystem should constantly self-innovate to achieve mutual integration and coordinated development.

\subsection{Integrate All Elements of Ecosystem and Promote Resource Sharing}

Based on the sharing economy, it promotes the innovation and development of smart retail, realizes the construction of multi-level ecosystem of technology, service, data and environment, promotes the integration of retail business ecosystem in the production link, the innovation and development of big data management mode and enterprise management concept, promotes the organic development of retail ecosystem, and forms a more efficient and optimized ecological mode. The core of sharing is to promote the business model and management concept of retail enterprises, and to promote the formation of emerging technology ecology such as big data, Internet and artificial intelligence. Therefore, for the smart retail ecosystem under the sharing economy, further enhance the sharing value, optimize the core retail ecological resources such as customer resources, channel resources, service resources and logistics resources Reasonable sharing, repeated use, and ultimately improving the efficiency of enterprise operation and 
consumer communication are one of the ways to promote further innovation of smart retail ecosystem.

\subsection{Develop Intelligent Technology and Improve Collaborative Development Level}

The Intelligent Retail is a new type of business relying on the Internet of things and big data, through collaborative sharing innovation mode, with the help of cloud computing and artificial intelligence technology, to promote industrial division, reconstruct industrial structure, and change industrial development mode. The value source of retail enterprises is more and more dependent on data, information, solutions and intelligent services. Intelligence is one of the main features of the New Retail business ecosystem. Only through the use of artificial intelligence, big data, mobile terminals and other technologies and tools to reconstruct and drive the elements of the New Retail business ecosystem, can we fundamentally promote the collaborative development of the elements in the Retail Business ecosystem level. The development of technology has promoted profound changes in the elements, structure, function and efficiency of retail industry.

\subsection{Promote Standardizing Construction and Smooth Business}

Without uniform standards, it is difficult to form synergy among business, data, resources and technology. Smart retail business ecosystem standardization includes: data format standardization, information transmission standardization, equipment and facilities standardization, payment standardization, business docking standardization, etc. We will promote the construction of standardization. We will work out unified product standards, service standards, operation standards and technical standards, open up industry and industrial technology boundaries, and promote the sharing and mutual recognition of technical standards within the system.

\section{Conclusion}

Each "species" in the commercial ecosystem plays a different role in the system, and each plays a different role, forming an ecosystem of interdependence, interdependence and common development. Similar to the natural ecosystem, every link in the business ecosystem is a part of the whole business ecosystem. Every enterprise will ultimately share the same fate with the business ecosystem. If any link is damaged, it will affect the balance and stability of the whole business ecosystem. In the New Retail environment, the effective operation of the Intelligent Retail business ecosystem depends on the application of artificial intelligence, big data, cloud computing, Internet of things and other technologies, integrating online and offline, giving full play to the convenience advantages of online retail and the experience advantages of offline physical retail, deeply mining customer needs, improving customer experience, and promoting the elements of the retail business ecosystem To realize the transformation from traditional retail industry to intelligent business ecosystem.

\section{Acknowledgements}

Supported by the 2018 Heilongjiang philosophy and social sciences research planning project (approval No. 18GLE464). 


\section{References}

[1] Moore J.F, Predators and Prey, "A New Ecology of Competition", Harvard Business Review, Vol.71, No.3, pp.74-80. May, (1993) DOI:10.1111/j.1744-1714.1993.tb00677.x

[2] Peltoniemi M., Vuori E., Editors, "Business Ecosystem as the New Approach to Complex Adaptive Business Environments", Proceedings of eBusiness research forum, pp.267-281, January (2004)

[3] Pierce ,Lamar, "Big Losses in Ecosystem Niches: How Core Firm Decisions Drive Complementary Product Shakeouts", Strategic Management Journal, December, Vol.30, No.3, pp.323-347. (2008) DOI: 10.2139/ssrn.1157054

[4] Hollander, Stanley C., "The Wheel of Retailing”, Journal of Marketing, Vol.25, No.1, pp.37-42. July (1960), DOI: $10.1177 / 002224296002500106$

[5] Hermann Haken. "Synergetics: the Secret of Natural Success. Translated by Dai Mingzhong", Shanghai Science Popularization press, Shanghai (1988)

[6] Zhou Fang, "Research on the Coupling Mechanism of Technology, Business Model and Brand Collaborative Innovation Based on Business Ecosystem", Business Economy Research. Vol.1, No.10, pp.108-109. May (2016) DOI: 10.3969/j.issn.1002-5863.2016.10.038. 
The Research on the Collaborative Development of Intelligent Retail Business Ecosystem 